\title{
The Role of Social Support in the Relationship Between Adolescents' Level of Loss and Grief and Well-Being
}

\author{
Firdevs Savi Çakar ${ }^{1}$ \\ ${ }^{1}$ Faculty of Education, Burdur Mehmet Akif Ersoy University, Burdur, Turkey \\ Correspondence: Firdevs Savi Çakar, Faculty of Education, Burdur Mehmet Akif Ersoy University, Istiklal \\ Yerleşkesi, Burdur, Turkey. E-mail: firdevssavi@hotmail.com
}

\author{
Received: July 5, $2020 \quad$ Accepted: September 7, $2020 \quad$ Online Published: November 23, 2020 \\ doi:10.5539/ies.v13n12p27 URL: https://doi.org/10.5539/ies.v13n12p27
}

\begin{abstract}
In this study, the model, developed to examine the role of social support in the relationship between adolescents' level of loss and grief and well-being, was tested. In this study, the descriptive research method was used, and its participants consisted of 216 adolescents who were high school students, in Turkey. Scales used in this study include Personal Information Form; Grief Scale; Five-Dimensional Well-Being Scale for Adolescents (EPOCH); Social Support Assessment Scale for Children and Adolescents (CASSS and Personal Information Form). The structural equation model was used to examine the mediator role of the social support in the association between grief and well-being among adolescents. It was found the hypothesized model fit the data well, and social support fully mediated in the association between grief and well-being. The high level of social support in the loss and mourning process of adolescents makes it easier to cope with grief and positively affects their well-beings. These results are important for focusing on adolescents who experience lost and grief, providing effective mental health services and demonstrating the importance of strengthening social support systems. Future studies with longitudinal follow-ups are suggested to explore actual causal relationships.
\end{abstract}

Keywords: loss, grief, well-being, social support, adolescent

\section{Introduction}

Today, it can be said that loss experiences are high due to wars, diseases, traumatic events and deaths due to negative economic, social and political developments, especially natural disasters all over the world. While the question of how the phenomenon of loss and grief affects the lives of adolescents as a universal phenomenon is tried to be answered in terms of adolescent mental health, more focus is needed to address the issue with short-term and long-term consequences on adolescents' development and harmony, as well as more focus is needed on the prevalence, effects and interventions of loss and mourning in adolescents.

\section{Background}

As a transition period, puberty requires navigating many areas and adapting to the resulting developmental challenges (Balk, 1996). It is a time of transformation that includes biological, psychological and social perspective (Weisz \& Hawley, 2002). The formation of a sense of identity and improving the self-form are cornerstones of spiritual development (Noppe \& Noppe, 2004). Although adolescence offers adolescents a number of opportunities for growth and development (Weisz \& Hawley, 2002), adolescents experience many negative life experiences and losses while trying to overcome the developmental crisis of the period, and they try to deal with the syllabus that arises after these losses (Hogan \& DeSantis, 2004). Accordingly, it should be noted that adolescents are at high risk both in relation to the developmental process and in terms of developing functional disorders related to the loss and the grieving process (Weisz \& Hawley, 2002).

\subsection{Loss and Grief}

Death is a loss as the end of life and causes grief in individuals (Thompson, 2002). The loss covers many areas of life outside death. Losses in the literature include primary losses (death, divorce/separation, loss of work, moving, etc.) and the secondary loss accompanying primary losses (loss of relationships, friendship, security, identity, finance, stability, role, support system, loss of hopes, dreams and expectations, etc.). It should be noted here that secondary losses are as important as primary losses, the effects of loss are decisive, and no matter what kind, all these losses are real and bring along the grief (Humphrey, 2017). Conceptually, grief is severe and 
prolonged pain that occurs after a loss (Weiss, 2001). In the grief, the individual suffers a deep sadness or sadness, this process is the aching of the soul and the suffering of the individual's mind (Abi-Hashem, 2017). Grief is also physical, cognitive, emotional, behavioral and spiritual responses that are given against a lost in a holistic manner (Balk, 2011).

The grieving process is individual; it can be experienced in different ways and times due to the dynamics of each individual's grieving process (Dominick et al. 2009-2010). Therefore, the variables that affect the adaptation of loss and mourning are particularly focused on the mourning process. Among these variables, age and development level (Ensel \& Lin, 2000; Humphrey, 2017) are important in announcing developmental diversity in the mourning process (Ensel \& Lin, 2000). The effect of death is generally limited due to the difference in detecting developmental death in children and adolescents, and this affects the grieving process (Dickens, 2014). Gender is highlighted in favor of women (Bennett et al., 2003). Another factor is how the loss occurs (Carr, House, Wortman, Nesse, \& Kessler, 2001) and especially sudden or severe deaths (such as suicides, violent deaths and loss of natural disasters) are indicated to have an effect on coping with loss and well-being (Humphrey, 2017). The degree of intimacy of loss is another factor (Humphrey, 2017), and in addition to the severe impact of parental loss (Harrison \& Harrington, 2001), sibling loss is the most tragic and least understood loss experience for the adolescent (Balk, Zaengle, \& Corr, 2011). In addition, peer loss is of particular importance to the adolescent and is important to the grieving process (Harrison \& Harrington, 2001). Another factor affecting the grieving process is the perceived level of social support, while low social support is an important risk factor for well-being, while it plays a more important role in the process of coping with the wound (Stroebe \& Schut, 2001), and it directly and indirectly affects post-mourning adaptation (Carr et al., 2001). In addition to these factors mentioned, factors such as adolescent's health, temperament, loss experience, mortality and how to make sense of loss, and coping level are associated with personal factors that may affect recovery after loss (Packman, Horsley, Davies, \& Kramer, 2006). In addition, the nature of the relationship with the lost person, the psychological history of the individual with loss experience, cultural characteristics are closely associated with the grieving process (Humphrey, 2017).

\subsection{Adolescent' Loss and Grief}

In general, loss and grieving conditions are critical cases capable of affecting important aspects of life in adolescence. For example, social relations, autonomy, self-image, trust and maturity are among the clear aspects of this effect (Balk, 2011). Because bereaved adolescents do not just struggle to transition to a new era developmentally during this period, they also try to cope with the loss (Balk, Zaengle, \& Corr, 2011). While adolescents' losses and coping with grieving process and returning to the old level of functionality may reduce well-being, decreased well-being may also complicate coping with grief. Indeed, it is emphasized that the behavioral problems that arise following adolescents' stressful life events are associated with a decrease in well-being (Suldo \& Huebner, 2004).

Although it is suggested that children and adolescents' forms of expressing grief are similar, but are different from adults (Corr, 2013), adolescents' process of coping with losses and grieving responses are much more complex than that of children and adults. These losses can cause more difficulties, especially with changes that accompany development in adolescence. The losses at a time when there are developmental struggles of adolescence, such as identity development, gaining autonomy, separation from parents, defining career choices and the formation of close relationships, have significant difficulties in the grieving process (Noppe \& Noppe, 2004). Another important factor in terms of the difference in this process is the adolescent's view on death. According to Raphael (1997), "death, according to the teenager, is a curse", because everything in adolescent's life emphasizes life, change, growth. The development of body, the excitement of developing thought processes, the attractive world of adulthood and power are now very close, and all of this makes death seem impossible for the adolescent. The teenager reluctantly confronts grief, as if he had been attacked, through encountering a reality that has no place in his world. Since the reality of death is often not a place in adolescents' lives, the grieving processes are different (Corr, 2013). Indeed, adolescents may react differently in the process of loss and grief; they can take attempts to suppress their existing feelings. Some of these reactions include idealizing the deceased, avoiding reminders of the person who is lost, thinking only good things towards the person who died (Worden, 2001).

Different reactions may occur in the period of development in the mourning process, and adolescents' responses to the law may differ from adults. In this respect, the reactions to loss in adolescents are classified as follows: Cognitive responses (regression, loss of certain skills, communication difficulties, confusion), emotional responses (increased dependence on others, sadness, depression and anxiety, guilt, anger and shame et al.), behavioral responses (childish behavior regression, obsessive and repetitive speech, aggression and 
disobedience, self-control or discipline, alcohol or drug use, reluctance to go to school), physical responses (headache, shock, sleep problems, lack of appetite, avoidance of others and social context, inability to deal with built-in and regular routines, etc.) (Weymont \& Rae, 2006).

Attig (1996) states that the deep loss of death means that life changes forever. Familial losses such as the death and divorce of family member/members are indicated. Among the major life events that most affect adolescents' well-being during this period (McCullough, Huebner \& Laughlin, 2000). Thus, in terms of protecting and strengthening adolescents' mental health, it is considered an important element of support to provide adolescents with healthy coping skills with lost and grief (Hansen, Cavanaugh, Vaughan, et al., 2009). Therefore, although grief after death and other casualties is considered a universal phenomenon, it should be taken into account how grief is experienced and the reactions shown against grief can become more complex when it comes to adolescents.

\subsection{Effects of Loss on Adolescents}

Adolescence refers to a crisis as a period of life characterized by confusion, confusion and uncertainty. The death of a loved one during this period, unlike adults and children, could create more rebellion in adolescents (Oltejenbruns, 2007). Increasing negative emotions after a significant loss can make identity formation difficult by increasing adolescent's vulnerability, threatening the meaning or beliefs of his/her life (McCarthy, 2007). However, adolescents can show their grief directly through their behavior and express their distress. Sometimes due to stress caused by the suffering, adolescents may turn to out-of-control behaviors such as anger explosions, crime-related actions, school denial, playback, risk-taking behavior, drug-taking and trying with the aim of drawing attention and reducing tension (Raphael, 1997). Adolescents in the grieving process can withdraw and isolate themselves, depending on the feeling different from their peers. These reactions can also be further enhanced by their feelings of isolation while limiting their opportunities to express their feelings and providing support from others (Davies, 2013).

On the other hand, the case of loss includes losses other than death, leading to a number of difficulties in non-death losses, disrupting the well-being of adolescents. Indeed, it is indicated that emotional losses other than parental death cause behavioral and emotional reactions in adolescents, with $63 \%$ of adolescents whose mothers are in prison suffer a loss of attachment (Poehlmann, 2005); separation of parents or divorce process also causes grieving reactions in children (ACATLGN_grief_and_loss). Similarly, it is stated that adolescents who lost their homes in the earthquake have intense negative behavioral reactions (Sabuncuoğlu, Çevikaslan, \& Berkem, 2003). It is challenging for adolescents in terms of their well-being at the loss of parents' work or loss of caretaker. It is indicated that, especially after losses, adolescents become more open to abuse, they have difficulty dealing with these losses, and they made direct towards alcohol or violence (Dizer, 2008). It is emphasized that that there is an increase in risky behaviors and criminal behaviors by worsening psychological outcomes with the decrease in post-loss social support (Walker \& Shaffer, 2007). In studies carried out with war-torn children and adolescents, among the most severe traumatic lives in terms of multiple losses, the importance of healthy functioning of psychosocial support mechanisms is emphasized in reducing the traumatic effect (Erden \& Gurdil, 2009).

\subsection{Well-Being in Adolescent}

The issue of well-being is discussed in conjunction with areas of well-being, goodness, state of goodness, subjective goodness and psychological well-being in positive psychology (Kern, Benson, Steinberg, \& Steinberg, 2016). Well-being involves a person's realization when faced with adversity and his/her potential for a meaningful life (Ryff \& Singer, 1996). While well-being is associated with the good life, it emphasizes that negative emotions are part of life and that it is not possible to have a constant well-being. Therefore, it refers to a way of life in which the individual takes on his/her own responsibility for maintaining, continuing and developing well-being in integrity (Rffy \& Keyes, 1995). As an auxiliary and partnering resource in dealing with negative emotions and sustaining life, it is clear that well-being (Huppert, 2009) will contribute positively to adolescent health. It will be important to focus on increasing the well-being of adolescents who especially experience loss and who are the process of grieving.

\subsection{Social Support in Adolescent}

Social support plays a highly functional role in human life during particularly stressful events, especially on mental health and together with its effect on emotions, cognition and behavior among individuals (Cohen, 1988). Cohen and Wills (1985) evaluates the impact of social support in two ways: First, in the main effect hypothesis, social relationships are beneficial for people under stress; having large social networks offers people regular positive experiences and socially rewarded roles in society. This type of support provides a positive effect on the 
sense of identity, purpose, meaning, belonging and self-esteem in terms of well-being. The second effect, the stress buffering hypothesis, has the effect of buffering social relationships. Social support plays a buffer between stressful situation and stress response. This effect takes into account both the various coping requirements that a stressful event may require, as well as the diversity of social resources that can (or cannot) be provided by social relationships. The buffering effect occurs when a person detects the availability of resources to help him respond to stressful events. Effective social support provided through adequate social networks can alleviate the effect of stress on individual's psychological state. The presence of an adequate network of social relationships strengthens people's health and well-being, increases coping by providing emotional or tangible support, and a protective mechanism (buffering mechanism) comes into play in the face of stress.

The social support may include family, relatives, friends, colleagues, mentors, community members, psychotherapists, social service support, support groups, traditional healers and religious/spiritual resources in a large field. In the case of grief, adolescents may experience a second loss without support from certain individuals (such as friends, teachers) who they think will provide support when they need them, which can further increase the grief (Humprey, 2017). Therefore, the significant effect of social support on adolescent development and harmony becomes much more important in the loss and grief process.

\subsection{Purpose of Study}

Losses and other traumatic life experiences with stress pose a risk to adolescents' psychosocial development process and well-being. Social and psychological support is considered very important so that adolescents can restructure this new situation that occurs with loss and adapt to loss. As emphasized in the above statements, considering the impact of adolescents' loss and grief process on their well-being, reducing the risk factors that play a role in adolescent loss and grief and increasing their well-being gain importance in preventative mental health studies. In this process, having a high level of social support appears to be an important factor in dealing with loss and grief. In this context, the aim is to reveal the direct and indirect effect of the social support in the relationship between adolescents' level of loss and grief and psychological well-being.

\subsection{Theoretical Model of the Research}

The aim of this research is to examine the mediating role of social support in the relationship between adolescents' level of loss and grief, and psychological well-being. For this purpose, the theoretical model created in the research contains four structures: Loss, grief level, psychological well-being and social support. The hypothesis developed to test the mediating role of social support is presented below:

H1: Social support has a mediating role in the relationship between loss, grief and psychological well-being in adolescents.

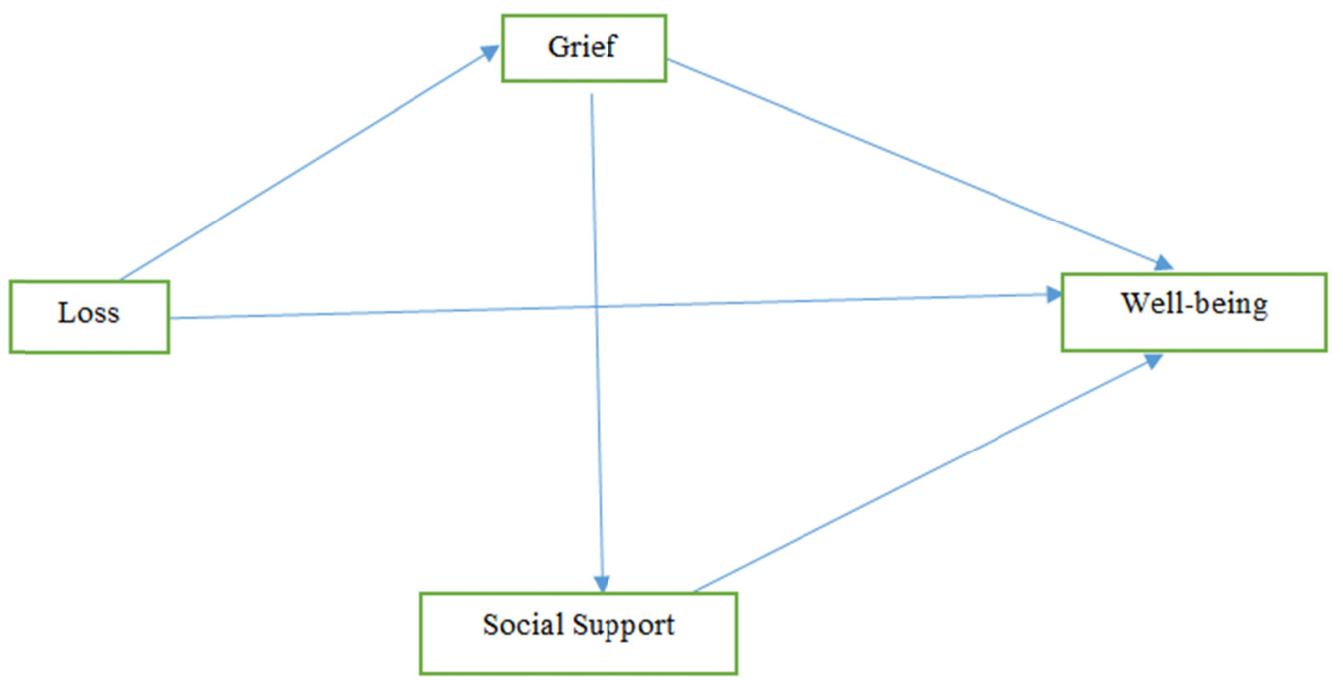

Figure 1. Theoretical model of the research

\section{Method}

This study is a descriptive study that examines relationships among variables. 


\subsection{Participants}

Participants of the study consisted of 216 high school students who attended to the 9th, 10th, and 11th grades of a high school determined using easy sample method. The participants consisted of 216 high school students, including 123 girls (56.9\%) and 93 boys (43.1 boys). Age distributions range from 14 to 18 ; the average age is 15.50. Distributions by grade level are as follows: 80 th graders (37\%), 7710 th graders $(35.6 \%)$, and 59 11th graders $(27.4 \%)$.

\subsection{Process}

During the process of data collection from participants, it was indicated that voluntariness was essential in the process, and informed consents were taken in writing, and personal information was not included in the process by indicating that their information would not be used outside of research within the scope of personal data confidentiality. For the application, support was received from the school psychological counselor, the application was carried out in a classroom environment as a group.

\subsection{Measures}

Personal Information Form; it consists of two parts. First, the study contains information towards determining adolescents' gender, age and class levels, as well as academic achievement level, parental work status, family income level, parent marital status, and whether they received psychological support in the last 1 year. The second part includes adolescents' loss experiences to determine their losses, and the adolescents were asked to state their losses. In this section, adolescents' loss experiences were evaluated using frequency and percentage values and presented in descriptive findings.

Grief Scale was developed to identify physical, emotional, intellectual and behavioral changes that occurred after the loss of a loved one or ones. The Scale is a 5-type Likert scale, consisting of a total of 35 items and four sub-dimensions. These sub-dimensions include physical, cognitive, behavioral and emotional responses shown in the face of grief. Cronbach alpha coefficient calculated to determine the internal consistency of the scale is .96. Retest reliability coefficient was found to be .84 (Balcı-Çelik, 2006).

Five-Dimensional Well-Being Scale for Adolescents (EPOCH) assesses adolescents' well-being in terms of characteristics such as engagement, perseverance, optimism, connectedness and happiness. Compliance index values calculated as a result of the scale's confirmatory factor analysis were found to be at an acceptable level ( $\mathrm{x}^{2}$ $=381.29, \mathrm{sd}=160, \mathrm{RMSEA}=.074, \mathrm{NFI}=.96, \mathrm{NNFI}=.98, \mathrm{CFI}=.98, \mathrm{IFI}=.98, \mathrm{RFI}=.96$ and $\mathrm{SRMR}=.052$ ). Factor loads of items on a scale range from .37 to .84 . Internal consistency coefficients for the sub-dimensions of the scale range from .72 to .88 . The internal consistency coefficient of the total score of the scale was calculated as .95 (Demirci \& Ekşi, 2015).

Social Support Assessment Scale for Children and Adolescents (C-SSAS) was developed by Dubow and Ullman $(1989 ; 1991)$ to assess children and adolescents' perceptions on the social support received from their families, friends (close friends and classmates) and teachers. Cronbach alpha reliability coefficient for the entire scale was found to be .93; test re-test reliability coefficient for the entire scale was found to be .49 ( $p<0.01)$. The two-half reliability of the scale (Guttman) was determined as .82 (Gökler, 2007).

\subsection{Data Analyses}

Prior to conducting the structural equation modeling, preliminary analyses were performed to examine the correlations between variables, descriptive statistics, and analysis assumptions. Normality was checked using skewness and kurtosis scores and their cut-off values (Curran, West \& Finch, 1996; Kline, 2015). Pearson correlation analysis was then performed to investigate the association between study variables. After conducting the preliminary analyses, the structural equation model was used to examine the mediator role of the social support in the association between grief and well-being among adolescents. Common data-model fit statistics and their cut-off scores were used to assess goodness of fit for structural model: comparative fit index (CFI) and Tucker-Lewis index (TLI) $\geq .90=$ adequate and $\geq .95=$ close data-model fit; root mean square error of approximation (RMSEA) $\leq .08=$ adequate, and $\leq .05=$ good data-model fit (Hooper, Coughlan \& Mullen, 2008; Kline, 2015). Findings from the structural model were also interpreted using the standardized path coefficients $(\beta)$ and squared-multiple correlations $\left(R^{2}\right): 01-.059=$ small, .06- $.139=$ moderate, and $\geq .14=$ large (Cohen, 1988). All analyses were performed using SPSS version 25 and AMOS version 24.

\section{Results}

This study tested a model developed to examine the role of social support in the relationship between adolescents' level of loss and grief and their psychological well-being. The findings of the study are as follows, 
respectively; the demographic findings of the participants, results of descriptive statistics and correlations, and finally the results of proposed model tested.

\subsection{The Participants' Demographic Characteristics}

When the findings of the participants' demographic characteristics are examined; participants evaluated their academic achievements, and 63 adolescents indicated their academic achievement at low level (27.3\%), 103 of them in moderate level (44.6\%), and 50 adolescents in high level (28.2\%). In addition, in the findings of adolescents' families, it was indicated that 95 of them had low family income (42.9\%), 106 of them had moderate level of income (47\%), and 15 of them had high level of income (11\%). While mothers of 116 participants $(52.5 \%)$ have a job, mothers of 100 participants $(47.5 \%)$ do not work; while fathers of 190 participants $(88.2 \%)$ have a job, fathers of 190 participants $(11.8 \%)$ do not work. When data on family integrity is examined; 26 adolescents' parents (12.03\%) are divorced; 176 adolescents' parents (81.48\%) live together, and the parents of 14 adolescents (6.48\%) live separately. In addition, when the data obtained on whether participants received psychological support in the last year was examined; it was determined that 29 participants $(13.42 \%)$ received psychological support, while 187 participants (86.58\%) did not receive support.

\subsection{Findings on Participants' Loss Experiences}

Participants were asked to indicate their loss experiences throughout their lives, and the findings were presented in Table 1.

Table 1. Findings on participants' lost experiences

\begin{tabular}{lcc}
\hline Lost Experiences & $\mathrm{f}$ & $\%$ \\
\hline Death (death of a close relative) & 113 & 48.9 \\
The death of someone loved outside the family & 94 & 40.07 \\
Parents' divorce/separation/leaving home & 27 & 11.7 \\
Exposure to violence/abuse in the family (physical-sexual-emotional-economic) & 13 & 5.6 \\
Exposure to violence/abuse outside of family (physical-sexual-emotional-economic) & 17 & 7.4 \\
Relocation-School Replacement & 55 & 23.8 \\
Loss of Health, Chronic Disease (Heart, Sugar, Kidney Illness) & 25 & 10.8 \\
Having Mental Illnesses & 23 & 10 \\
Loss of Academic Success & 62 & 26.8 \\
Natural Disaster (Earthquake, Flood, Fire) & 72 & 31.2 \\
Leaving your favorite friends & 85 & 36.2 \\
Leaving your girlfriend & 52 & 22.5 \\
School escape/School drop & 12 & 5.2 \\
Having an accident/Organ loss after accident & 7 & 3 \\
Parental Loss of Work & 22 & 9.5 \\
Addiction (smoking, alcohol, substance abuse) & 24 & 10.4 \\
Economic Losses/Foreclosure to the Family & 10 & 4.3 \\
Witnessing the loss of someone loved so much & 59 & 25.5 \\
Other losses (the death of your pet, grow...) & 97 & 43.9 \\
\hline
\end{tabular}

As shown in Table 1, loss experiences reported by participants are as follows: losing a close relative by death reported by 113 participants $(48.9 \%)$; the death of someone loved outside the family reported by 94 participants (40.07\%); experiencing separations in the form of divorce/separation/leaving home by 27 participants (11.7\%); being subjected to violence or abuse in the family (physical, sexual, emotional and economic abuse) by 13 participants (5.6\%); being exposed to violence or abuse outside of family (physical, physical, sexual, emotional and economic abuse exposure) by 17 participants (7.45\%); relocation and school replacement by 55 participants (23.8\%); experiencing health problems and loss of health/chronic diseases by 25 participants (10.8\%); experiencing mental problems by 23 participants (10\%); loss of academic success by 62 participants (26.8\%); natural disasters (earthquakes, earthquakes, earthquakes, flooding, fire) by 72 participants (31.2\%); separation from their favorite friends by 85 participants $(36.2 \%)$; leaving their loved ones by 52 participants $(22.5 \%)$; school escape/school leave by 12 participants (5.2\%); traffic accident by 7 participants (3\%); their parents experiencing job loss by 22 participants (9.5\%); experiencing addiction (smoking, alcohol, substance) by 24 participants (10.4\%); economic losses/foreclosure to the family by 10 participants $(4.3 \%)$; close witnessing to 
the loss of someone they love by 59 participants (25.5\%); and in the form of other losses (the death of their pet, growing...) by 97 participants (43.9\%).

\subsection{Descriptive Statistics of the Study and Correlation Results}

Descriptive statistics of the study and correlation results are presented Table 2.

Table 2. Descriptive statistics and correlations

\begin{tabular}{lcccccccc}
\hline & \multicolumn{9}{c}{ Descriptive statistics } & \multicolumn{3}{c}{ Correlations (r) } \\
\hline Scales & $\alpha$ & Mean & SD & Skew. & Kurt. & Grief & Well-being & Support \\
\hline Loss & - & 3.847 & 3.131 & 1.403 & 2.922 & $235^{* *}$ & $-.166^{*}$ & -.112 \\
Grief & .932 & 78.560 & 26.980 & .150 & -.669 & - & $-.135^{*}$ & $-.199^{* *}$ \\
Well-being & .897 & 64.449 & 16.295 & -.029 & -.418 & & - & $.383^{* *}$ \\
Social Support & .896 & 142.708 & 22.443 & .609 & -.513 & & & - \\
\hline
\end{tabular}

${ }^{*} p<.05,{ }^{* *} p<.001$.

As seen in Table 2, findings of the preliminary analysis showed that skewness scores ranged between 1.403 and -.029 ; kurtosis scores ranged between -.513 and 2.922 . It suggested that all variables in the study were relatively normally distributed (Curran et al., 1996; Kline, 2015). Additionally, all measures of the study had strong internal reliability $(\alpha)$ estimates, ranging from .896 to .932 (Grief Scale is .932; Well-being Scale is .897; Social Support Scale is. 896).

In Table 2, correlation results revealed that loss was significantly and negatively associated with youth well-being $(r=-.166, p<.05)$ and positively related to grief $(r=.235, p<.001)$. There was also a significant and negative correlation between grief and social support $(r=-.135, p<.05)$ and well-being $(r=-.199, p<.001)$ of adolescents.

\subsection{The Results of Proposed Model Tested}

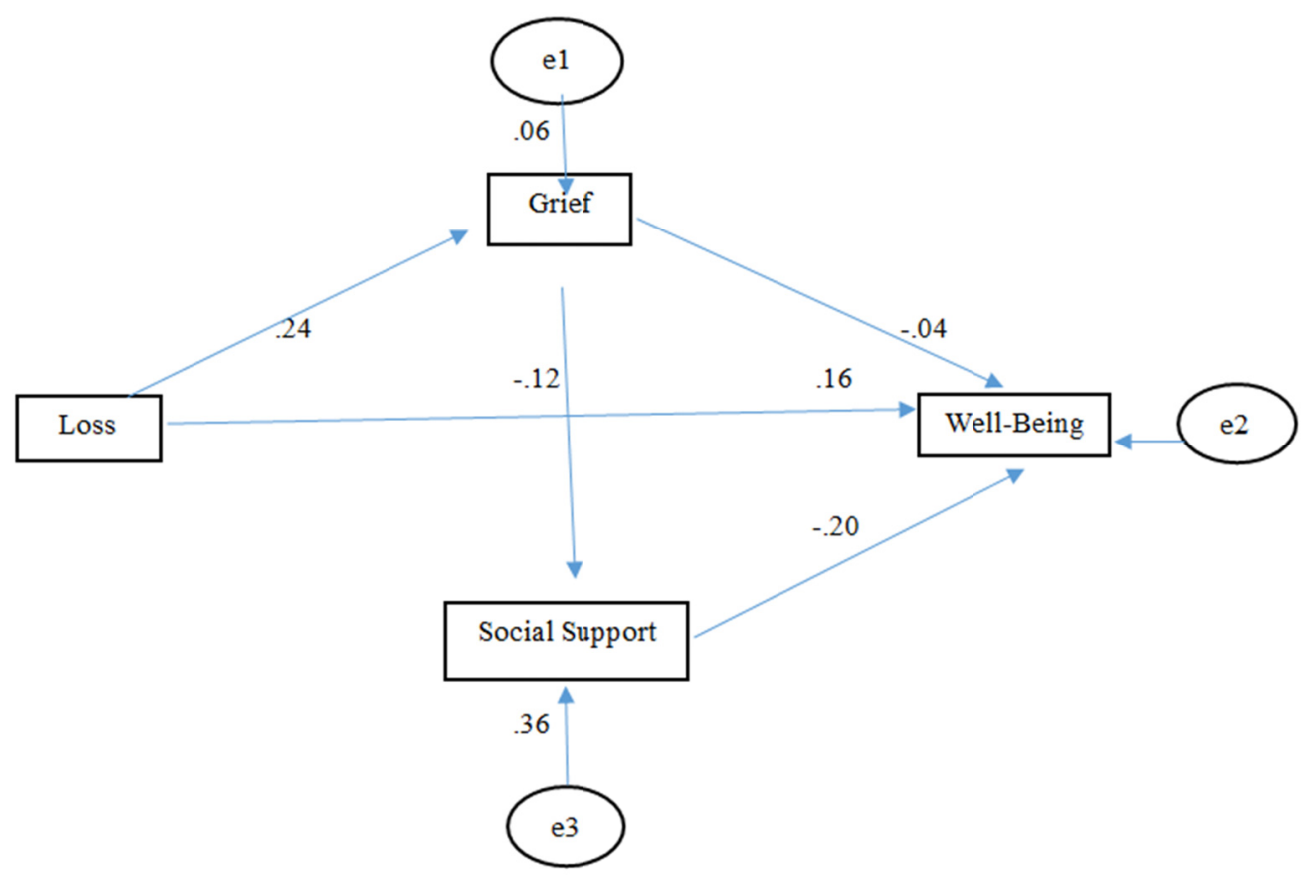

Figure 2. Structural equation model equation model demonstrating the association between variables

After examining the descriptive statistics and correlations, the proposed model (see Figure 1) tested using structural equation modeling, indicating that the model had excellent data-model fit statistics $\left(\chi^{2}=1.022, d f=1\right.$, $p=.312$, TLI $=.998 \mathrm{CFI}=1.00$, RMSEA $[95 \% \mathrm{CI}]=.010[.00, .18])$. Results from these analyses showed that loss was a significant and positive predictor of grief $(\beta=.24, p<.001)$, accounting for $6 \%$ of the total variance in 
grief. Grief directly and significantly predicted the social support of adolescents $(\beta=-.20, p<.001)$ but did not significantly predict their well-being $(\beta=-.04, p=.582)$. Social support fully mediated in the association between grief and well-being $(\beta=.36, p<.001)$. Additionally, the loss was not a significant predictor of well-being $(\beta=-.12$, $p=.070$ ). Grief accounted for $4 \%$ of the total variance in social support, and all variables, together, accounted for $16 \%$ of the total variance in well-being. These results suggested the importance of social support in explaining the effect of loss and grief on adolescent well-being. The structural model indicating the mediating effect of social support on the link of grief with well-being is presented in Figure 2.

\section{Discussion}

This study was conducted to examine the role of the role of social support in the relationship between adolescents' level of loss and grief and their psychological well-being. When the results of the study were examined, it was determined that, first, adolescents had different loss experiences in many areas such as death and outside death, depending on prevalence of loss experiences among adolescents, and that they feel grief depending on these experiences. This situation shows that the prevalence of adolescents' loss experiences is important in terms of recognizing the increasing psychological support needs due to grief. In the world, when were examine the results on the prevalence of losses, there are very striking results. Due to factors such as wars, natural disasters, epidemics, social turmoil and economic problems, etc., the number of orphans in the world is increasing day by day. According to 2015 figures from the United Nations (UN), there are more than 140 million children with parental losses in the world (https://www.un.org.). It is stated that at least $6.5 \%$ of children around the world have at least one parental loss (WHO, 2017). It was determined that similar findings were found in the study conducted by Akyüz (2019); 44.9\% of adolescents lost any relatives (parents, brother, grandmother/grandfather, aunt, uncle), experienced levels of grief, they experienced moderate cognitive changes and levels of behavioral changes due to grief. These results are important for adolescents to demonstrate the prevalence of loss experiences and the importance of understanding the grieving process. Although these results show the prevalence of death-related losses, we can see how important the phenomenon of loss and mourning in adolescents is, with the prevalence of non-death losses.

In the study, a negative and meaningful relationship was determined between adolescents' loss and grieving process and their well-being. In parallel with this result, it was stated in other studies revealing the impact of the level of loss on well-being that adolescents' losses and the grief after these losses were associated with many problems in terms of psychological well-being. It is noted that especially loss experiences such as loss of experience, divorce, childhood trauma, decreased school success and economic level negatively affect adolescents' well-being (Harrison \& Harrington, 2001). It is also emphasized that adolescents are more likely to experience symptoms of psychopathology in the future as well as problems such as anxiety, depression and post-traumatic stress disorder similar to those of adults after loss (Erden \& Gürdil, 2009). Among these problems are crime, anger, compliance problems, suicide, alcohol and smoking, school leave and antisocial behavior, drug use, risky sexual relationships (Noppe \& Noppe, 2004; Walker \& Shaffer, 2007; Worden, 2001). Based on these results, as the loss experiences of adolescents increase, it is observed that they face many problems and their well-being decreases.

In the field literature, this finding is supported by studies that emphasize low levels of well-being as the level of loss and grief increases (Hughes \& Waite, 2009). The emergence of many mental, physical and behavioral symptoms for adolescents, especially during the loss and mourning process, can contribute to the decrease in well-being due to the inability or prolongation of the grief process in a healthy way. Because the inability to deal with loss can slow down the adolescent's personality development; it may cause him/her to lose family, school and social functionality (Dyregrov \& Dyregrov, 2008). The intense occurrence of potentially negative emotions during the loss and grief process can make it difficult for adolescents to manage these feelings effectively, leading to a decrease in psychological well-being. As a matter of fact, the high negative sensation expresses individual's low well-being and unhappiness; it can also interfere with the functionality of the individual as an indication that the individual's life is deteriorating (Diener, 2006). Therefore, it is especially important that adults realize that even small losses in children and adolescents can have significant effects and then affect how they react to large losses (Weymont \& Rae, 2006). Therefore, it will be important to focus on well-beings of adolescents' experiencing loss and grief.

In another finding of the study, it was determined that there was a negative and meaningful relationship between grief and social support. This result is important for adolescents to reveal that the level of grief will decrease as social support increases in the process of loss and grief. Reviewing the literature; it is emphasized that a person with enough sources of social support feels better and copes with stress conditions more successfully (Cohen, Gottlieb \& Underwood, 2000), that family support is the predictor of general psychological stress and emotional 
problems (Demaray, Malecki, Davidson, Hodgson, \& Rebus, 2005). It should also be noted that there may be an increase in the need for social support the adolescent who loses the person he/she loves, and the adolescent may be more focused on receiving help from social bonds such as family, relatives or friends who are more personal. Losses, such as parental death, divorce or abandonment, can mean a loss of social support in adolescents and lead to a decrease in their psychological health and well-being. On the other hand, it should be noted that adolescents may need professional assistance, especially when social support networks are not sufficient, and adolescents do not want to reflect their painful, sad and grieved state to people around them (Benkel, Wijk, \& Molander, 2009).

In the grief literature, it is indicated that the role of other/surviving parent is important in the child or adolescent's compliance with the death of a family member. However, grieving parents have many tasks to deal with their children's loss, maintaining the continuity of the family as well as maintaining their own grief and managing family and friend relationships (Horsley \& Patterson, 2006). Therefore, adolescents may not get enough support from their grieving parents in this process. If there is not enough support after the loss, surviving children and adolescents suffer double loss, both the death of a family member and a loss of support from their grieving parents (DeVita-Raeburn, 2004). At the same time, grieving adolescents may try to camouflage their parents' happiness and grief as a defense mechanism to protect them (Balk, Zaengle, \& Corr, 2011). Being emotionally isolated from parents during this period will be risky for adolescent harmony and well-being as it hampers the integration and restructuring in the grieving process (Charles \& Charles, 2006).

In the study, it was determined that there was a significant relationship between the social support and well-being that adolescents perceive. According to this result, it is seen that high levels of social support for adolescents contribute to psychological well-being. One study found that the level of social support received from the family is the best indicator of emotional problems in early adolescence (Helsen, Vollebergh, \& Meeus, 2000), there is a positive-oriented significant relationship between social support and positive emotions (feeling good, positive perception of events, mental health, etc.) (Meehan, Durlak, \& Bryant, 1993). Stress-protective effect of social support (Cohen \& Wills, 1985), because of creating difficulty in dealing with stressful situations, thus contributing to the individual's physical and psychological well-being (Diener, 2006), social support, social networks and interpersonal relationships are considered important variables for well-being (Murphy \& Murphey 2006). It is indicated that social support is a strong predictor of well-being in terms of containing assistance from close people when an individual is faced with a problem or wants to relax emotionally (Kim, 2000), that being in a social network will help avoid many negative experiences and allows adolescents to experience more positive emotions (Cohen \& Wills, 1985).

While it is emphasized that social support is associated with variables with positive development in adolescents (Wentworth \& Parks, 2006), the concept of high self-esteem is positively associated with high level of social skills and adaptation (Demaray \& Malecki, 2002); it is seen that insufficient social and emotional support (inability to accept, lack of being understood, emotional isolation, lack of empathy, etc.) is the predictor of behavioral problems and non-compliance in adolescents, and an important risk factor in terms of well-being (Crosnoe \& Needham, 2004). In addition, it is emphasized that high family and friend support and positive family relationships significantly predict subjective and psychological well-being (Cenkseven \& Akbaş, 2007). It was found in another study that parental loss and divorce were associated with low levels of physical and mental well-being, divorced family children had lower good formation, greater difficulty in compliance and more conflict in family relationships than children of families living together (Hetherington, 2003). These results are important in terms of showing that strengthening social support sources and supporting adolescents in effective use of social support will increase their well-being.

As a source of social support, schools and teachers provide a very important boost in responding to crises and traumas affecting young people because of their relationships, and in dealing with the loss and grief they experience. Adolescents need more help from their peers as well as their teachers to make sense of their world after loss (Rowling, 2008). In this context, social support plays an important protective role in the grieving process with the school teacher and peer relations in which adolescents are in intense relations. According to Humprey (2017), it is important to help individuals in the process of reaching adequate social support resources. These results are important in terms of emphasizing the fact that adequate social support has a very important role in adolescents in the mourning process; there is a necessity for effective prevention and intervention studies towards strengthening mental health by increasing adolescents' well-being and social support during grieving process.

In terms of social support, it is also very important to see the need for peer relationships increasing in the nature of adolescence. As a matter of fact, peer support is also very important for good formation as social and 
emotional support. That is because peer support is associated with low emotional distress (Wentzel, 1998), high subjective well-being and positive feelings (Chou, 1999), and high self-esteem (Lackovic-Grgin \& Dekovic 1994). As peer support increases, while there is a decrease in stress and psychological symptoms, the level of harmony and coping increases. Therefore, it is also considered important to strengthen peer support in grieving adolescents, to give them the opportunity to form supportive relationships with their peers, and to help more bereaved family members. This is especially critical for the adolescent in the process of loss and grief. LaFreniere and Cain (2015) indicated that adolescents in grief had better sources of support for their close friends; adolescents were more open and willing to talk about death with a close friend. As the natural support of adolescents in grief who have experienced parental loss in particular, the peer group, which is not directly affected by the death of their parent, is a continuous and empowering booster to the adolescent. In parallel with this statement, it is reported that $48 \%$ of grieving teens receive the highest level of support from a peer (Gray, 1989), that adolescents prefer to be with their peers to get rid of their grieving families at home during the grief process (Christ, 2000).

In the results obtained in the research's mediation model test, it was determined that social support in adolescents was a complete mediating role in the relationship between grief and well-being. According to this finding, the high level of social support in the loss and mourning process of adolescents makes it easier to cope with grief and positively affects their well-beings. In the studies that support this result, it has been indicated that, while it is emphasized that social support resources that are owned can change the negative effect because it adds multiple options to the connection between the stressful event and the result by affecting the way an individual copes, it reduce the risk of psychological discomfort (Dalgard, Bjørk, \& Tambs, 1995). Maier and Lachman (2000) also indicated in their study that family support as a source of social support plays a mediating role in the relationship between divorce and well-being. Here, the protective and buffering effect of social support in the event of a person's stress exposure, as well as the effect of maintaining mental health by reducing the negative impact of stressful life events (Lin, Thompson, \& Kaslow, 2009) is a significant effect for adolescents in the grief process. In the findings in the form of high social support and health and low levels of psychopathology (Eisengart, Singer, Fulton, \& Baley, 2003), they reveal the importance of social support in the grief process for adolescents (Benkel, Wijk, \& Molander, 2009). In addition, it is stated that social support for the grieving adolescent acts as a protective factor, and that having enough social support in and around the family significantly affects the grieving process and adolescent's compliance with loss (Worden, 2001). Wight, Botticello, and Aneshensel (2006) have found that high levels of perceived social support from family, friends or other adults have a mental health protective effect for adolescents coming from low socio-economic level, and that social support decreases disadvantages of socio-economic level on mental health.

\subsection{Implications of the Study}

Consequently, this research found that level of loss and grief in adolescents and social support predict well-being significantly, and it has a full intermediary effect on the relationship between grief and well-being. These results reveal that social support is an important variable in announcing the impact of loss and grief on adolescents' well-being. Richman, Rosenfeld and Bowen (1998) emphasize the importance of two important functions of social support to contribute to harmony and development in all individuals and to protect against stress. In this context, in adolescents who experience loss and need more social support, it can be thought that low social support will be negatively reflected in adolescent's compliance and development, as well as the adolescent will be vulnerable to the loss-related stress. In this sense, it is seen how important adequate social support has become in increasing psychological well-being for adolescents in the grieving process.

\subsection{Limitations}

There are some limitations to the research. First, it is thought that reaching participants using an easily accessible sampling method will create a limit on the generality of the findings. Therefore, it is important to work with more inclusive and different sample groups in future studies. It is thought as another limitation that the participants are made up of adolescents with loss and grief and who continue to secondary education, and that adolescents other than high school education are excluded from this study.

\section{References}

Abi-Hashem, N. (2017). Grief, bereavement, and traumatic stress as natural results of reproductive losses. Issues L. \& Med., 32, 245.

Akyüz, G. A. (2019). Investigation of Emotional Regulation and Risk Behaviors of Subjective Well-Being in Adolescents with and Without Lost and Mourning Experiences (Master's thesis, Burdur Mehmet Akif Ersoy University Institute of Education Sciences). 
Aldemir, A., \& Balcı-Çelik, S. (2020). Üç Boyutlu Katkı Ölçeğinin Türkçe 'ye Uyarlanması: Geçerlik ve Güvenirlik Çalışması. Kastamonu Education Journal, 28(1), 539-548. https://doi.org/10.24106/kefdergi.3763

Aneshensel, C. S., \& Frerichs, R. R. (1982). Stress, support, and depression: A longitudinal causal model. $\begin{array}{lllll}\text { Journal of Community } & \text { Psychology, } & \text { 10(4), } & \text { 363-376. }\end{array}$ https://doi.org/10.1002/1520-6629(198210)10:4<363::AID-JCOP2290100407>3.0.CO;2-8

Attig, T. (1996). How we grieve: Relearning the world. Oxford University Press. https://doi.org/10.1093/acprof:oso/9780195074567.001.0001

Balcı-Çelik, S. (2006). Mourning Scale: Validity and reliability study. Turkish Psychological Counseling and Guidance Journal, 3(25), 105-114.

Balk, D. E. (2011). Helping the bereaved college student. New York: Springer Publishing.

Balk, D. E., Zaengle, D., \& Corr, C. (2011). Strengthening grief support for adolescents coping with a peer's death. School Psychology International, 32(2), 144-162. https://doi.org/10.1177/0143034311400826

Benkel, I., Wijk, H., \& Molander, U. (2009). Managing grief and relationship roles influence which forms of social support the bereaved needs. American Journal of Hospice and Palliative Medicine ${ }^{\circledR}, 26(4), 241-245$. https://doi.org/10.1177/1049909108330034

Bennett, K. M., Hughes, G. M., \& Smith, P. T. (2003). I think a woman can take it: Widowed men's views and experiences of gender differences in bereavement. Ageing International, 28(4), 408-424. https://doi.org/10.1007/s12126-003-1012-x

Carr, D., House, J. S., Wortman, C., Nesse, R., \& Kessler, R. C. (2001). Psychological adjustment to sudden and anticipated spousal loss among older widowed persons. The Journals of Gerontology Series B: Psychological Sciences and Social Sciences, 56(4), S237-S248.https://doi.org/10.1093/geronb/56.4.S237

Cenkseven, F., \& Akbaş, T. (2007). Investigation of the predictors of subjective and psychological well-being in university students. Turkish Journal of Psychological Counseling and Guidance, 3(27), 43-62.

Charles, D. R., \& Charles, M. (2006). Sibling loss and attachment style-An exploratory study. Psychoanalytic Psychology, 23(1), 72-90. https://doi.org/10.1037/0736-9735.23.1.72

Chou, K. L. (1999). Social support and subjective well-being among Hong Kong Chinese young adults. Journal of Genetic Psychology, 160(3), 319-331. https://doi.org/10.1080/00221329909595402

Christ, G. (2000). Healing children's grief: Surviving a parent's death from cancer. New York: Oxford University Press. https://doi.org/10.1093/acprof:oso/9780195105919.001.0001

Cohen, J. (1988). Statistical power analysis for the behavioral sciences (2nd ed.). Hillsdale, NJ: Lawrence Erlbaum.

Cohen, S. (1988). Psychosocial models of the role of social support in the etiology of physical disease. Health psychology, 7(3), 269. https://doi.org/10.1037/0278-6133.7.3.269

Cohen, S., \& Wills, T. A. (1985). Stress, social support, and the buffering hypothesis. Psychological bulletin, 98(2), 310. https://doi.org/10.1037/0033-2909.98.2.310

Corr, C. A. (2013). What do we know about grieving children and adolescents? In K. J. Doka (Ed.), Living with grief: Children, adolescents and loss (pp. 21-33). New York, NY: Routledge. https://doi.org/10.4324/9780203754818

Crosnoe, R., \& Needham, B. (2004). Holism, contextual variability, and the study of friendships in adolescent development. Child Development, 75, 264-279. https://doi.org/10.1111/j.1467-8624.2004.00668.x

Curran, P. J., West, S. G., \& Finch, J. F. (1996). The robustness of test statistics to nonnormality and specification error in confirmatory factor analysis. Psychological Methods, 1(1), 16-29. https://doi.org/10.1037/1082-989X.1.1.16

Dalgard, O. S., Bjork, S., \& Tambs, K. (1995). Social support, negative life events and mental health. The British Journal of Psychiatry, 166, 20-34. https://doi.org/10.1192/bjp.166.1.29

Davies, B. (2013). Sibling bereavement: We are grieving too. In K. J. Doka, \& J. D. Gordon (Eds.), Living with grief: Children, adolescents and loss (pp. 231-241). Florence: Taylor and Francis.

Demaray, M. K., \& Malecki, C. K. (2002). Critical levels of perceived social support associated with student 
adjustment. School psychology quarterly, 17(3), 213-241. https://doi.org/10.1521/scpq.17.3.213.20883

Demaray, M. K., Malecki, C. K., Davidson, L. M., Hodgson, K. K., \& Rebus, P. J. (2005). The Relationship Between Social Support and Student Adjustment: A Longitudinal Analysis. Psychology in the Schools, 42(7), 691-706. https://doi.org/10.1002/pits.20120

DeVita-Raeburn, E. (2004). The Empty Room: Surviving the Loss of a Brother or Sister at Any Age. Scribner, New York.

Dickens, N. (2014). Prevalence of complicated grief and posttraumatic stress disorder in children and

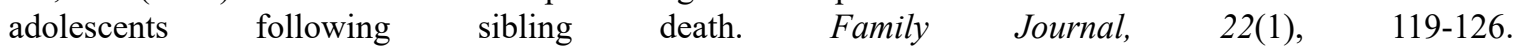
https://doi.org/10.1177/1066480713505066

Diener, E. (2006). Guidelines for National Indicators of Subjective Well-Being and Ill-Being. Journal of Happiness Studies, 7(4), 397-404. https://doi.org/10.1007/s10902-006-9000-y

Dizer, D. (2008). Investigation of High School Adolescents in Sakarya Province after 1999 Marmara Earthquake Detection, Social Support Systems and Symptoms of Hopelessness (Unpublished master thesis). Maltepe University Institute of Social Sciences, Istanbul.

Dominick, S. A., Irvine, A. B., Beauchamp, N., Seeley, J. R., Nolen-Hoeksema, S., Doka, K. J., \& Bonanno, G. A. (2010). An internet tool to normalize grief. OMEGA-Journal of Death and Dying, 60(1), 71-87. https://doi.org/10.2190/OM.60.1.d

Dyregrov, K., \& Dyregrov, A. (2008). Effective grief and bereavement support. London: Jessica Kingsley.

Eisengart, S. P., Singer, L. T., Fulton, S., \& Baley, J. E. (2003). Coping and psychological distress in mother of very low birth weight young children. Parenting Science and Practice, 3(1), 49-72. https://doi.org/10.1207/S15327922PAR0301_03

Ensel, W. M., \& Lin, N. (2000). Age, the stress process, and physical distress: The role of distal stressors. Journal of aging and health, 12(2), 139-168. https://doi.org/10.1177/089826430001200201

Erden, G., \& Gürdil, G. (2009). Trauma responses observed in children and adolescents after the war experiences and psycho-social assistance suggestions. Turkish Psychological Articles, 12(24), 1-13.

Gökler, I. (2007). Adaptation study of the Turkish version of the Social Support Evaluation Scale for Children and Adolescents: Factor structure, validity and reliability. Journal of Child and Youth Mental Health, 14(2), 90-99.

Gray, R. E. (1989). Adolescents' perceptions of social support after the death of a parent. Journal of Psychosocial Oncology, 7, 127-144. https://doi.org/10.1300/J077v07n03_09

Hansen, N. B., Cavanaugh, C. E., Vaughan, E. L., Connell, C. M., Tate, D. C., \& Sikkema, K. J. (2009). The influence of personality disorder indication, social support, and grief on alcohol and cocaine use among HIV-positive adults coping with AIDS-related bereavement. AIDS and Behavior, 13(2), 375-384. https://doi.org/10.1037/a0013168

Harrison, L., \& Harrington, R. (2001). Adolescents' bereavement experiences. Prevalence, association with depressive symptoms, and use of services. Journal of Adolescence, 24(2), 159-169. https://doi.org/10.1006/jado.2001.0379

Helsen, M. J. E., Vollebergh, W. A. M., \& Meeus, H. J. W. (2000). Social support from parents and friends and emotional problems in adolescence. Journal of Youth and Adolescence, 29(3). https://doi.org/10.1023/A:1005147708827

Hetherington, E. M. (2003). Social support and the adjustment of children in divorced and remarried families. Childhood, 10(2), 217-236. https://doi.org/10.1177/0907568203010002007

Hogan, N., \& DeSantis, L. (2004). Adolescent sibling bereavement: Toward a new theory. In C. Corr, \& D. Balk (Eds.), Handbook of Adolescent Death and Bereavement (pp. 173-195). New York: Springer Publishing Company.

Hooper, D., Coughlan, J., \& Mullen, M. R. (2008). Structural equation modelling: guidelines For determining model fit. Electronic Journal of Business Research Methods, 6(1), 53-60.

Horsley, H., \& Patterson, T. (2006). The effects of a parent guidance intervention on communication among adolescents who have experienced the sudden death of a sibling. American Journal of Family Therapy, 34(2), 119-137. https://doi.org/10.1080/01926180500301519 
Hughes, M. E., \& Waite, L. J. (2009). Marital biography and health at mid-life. Journal of health and social behavior, 50(3), 344-358. https://doi.org/10.1177/002214650905000307

Humphrey, K. M. (2017). Counseling skills for loss and mourning (Translation Ed. Tanhan, F.). Nobel Academic Publishing. Ankara.

Huppert, F. A. (2009). Psychological well-being: Evidence regarding its causes and consequences. Applied Psychology: Health and Well-Being, 1(2), 137-164. https://doi.org/10.1111/j.1758-0854.2009.01008.x

Kern, M. L., Benson, L., Steinberg, E. A., \& Steinberg, L. (2016). The EPOCH Measure of Adolescent Well-Being. Psychological Assessment, 28(5), 586-597. https://doi.org/10.1037/pas0000201

Kim, J. (2000). Social change and psychologycal wellbeing: A structural equation modeling (Doctoral thesis). University of Hawai, Department of Psychology, Hawai.

Kline, R. B. (2015). Principles and practice of structural equation modeling. New York, NY: Guilford.

Lackovic-Grgin, K., \& Dekovic, M. (1994). Pubertal status, interaction with significant other, and self-esteem of adolescent girls. Adolescents, 29(115), 691-700.

LaFreniere, L., \& Cain, A., (2015). Parentally bereaved children and adolescents: the question of peer support. Journal of Death and Dying, 71(3), 245-271. https://doi.org/10.1177/0030222815575503

Lin, J., Thompson, M. P., \& Kaslow, N. J. (2009). The mediating role of social support in the community environment psychological distress link among low-income African American women. Journal of Community Psychology, 37(4), 459-470. https://doi.org/10.1002/jcop.20307

Maier, E. H., \& Lachman, M. E. (2000). Consequences of early parental loss and separation for health and well-being in midlife. International Journal of Behavioral Development, 24(2), 183-189. https://doi.org/10.1080/016502500383304

McCarthy, J. R. (2007). 'They all look as if they're coping, but I'm not': The relational powerlessness of 'youth' in responding to experiences of bereavement. Journal of Youth Studies, 10(3), 285-303. https://doi.org/10.1080/13676260701262574

McCullough, G., Huebner, E. S., \& Laughlin, J. E. (2000). Title life events, self-concept, and adolescents positive subjective well-being. Psychology in the Schools, 37, 281-290. https://doi.org/10.1002/(SICI)1520-6807(200005)37:3<281::AID-PITS8>3.0.CO;2-2

Meehan, M. P., Durlak, J. A., \& Braynt, F. B. (1993). The relationship of social support to perceived control and subjective mental health in adolescents. Journal of Community Psychology, 21, 49-55. https://doi.org/10.1002/1520-6629(199301)21:1<49::AID-JCOP2290210106>3.0.CO;2-I

Murphy, H., \& Murphey, E. K. (2006). Comparing quality of life using the World Health Organization Quality of Life measure (WHOQOL-100) in a clinical and non-clinical sample: Exploring the role of self-esteem, self-efficacy and social functioning. Journal of Mental Health, 15(3), 289-300. https://doi.org/10.1080/09638230600700771

Noppe, I. C., \& Noppe, L. D. (2004). Adolescent Experiences with Death: Letting Go of Immortality. Journal of Mental Health Counseling, 26(2), 146-167. https://doi.org/10.17744/mehc.26.2.py2tk0kmay1ukc3v

Oltjenbruns, K. A. (2007). Lifespan issues and loss, grief, and mourning. Part 1: The importance of a developmental context: Childhood and adolescence as an example. In D. Balk, C. Wogrin, G. Thornton, \& D. Meagher (Eds.), Handbook of thanatology. The essential body of knowledge for the study of death dying, and bereavement (pp. 143-149). New York: Taylor \& Francis Group.

Packman, W., Horsley, W., Davies, B., \& Kramer, R. (2006). Sibling bereavement and continuing bonds. Death Studies, 30, 817-841. https://doi.org/10.1080/07481180600886603

Poehlmann, J. (2005). Children's family environments and intellectual outcomes during maternal incarceration. The Journal of Marriage and Family (JMF), 67(5), 1275-1285. https://doi.org/10.1111/j.1741-3737.2005.00216.x

Raphael, B. (1997). The interaction of trauma and grief. In D. Black, M. Newman, J. Harris-Hendriks, \& G. Mezey (Eds.), Psychological trauma: A developmental approach (pp. 31-43). Gaskell/Royal College of Psychiatrists.

Richman, J. M., Rosenfeld, L. B., \& Bowen, G. L. (1998). Social support for adolescents at risk of school failure. Social Work, 43(4), 309-323. https://doi.org:10.1093/sw/43.4.309 
Rowling, R. (2008). Linking spirituality, school communities, grief and well-being. International Journal of Children Spirituality, 13(3), 241-251. https://doi.org/10.1080/13644360802236482

Ryff, C. D., \& Keyes, C. L. M. (1995). The structure of psychological well-being revisited. Journal of Personality and Social Psychology, 69, 719-727. https://doi.org/10.1037//0022-3514.69.4.719

Ryff, C. D., \& Singer, B. (1996). Psychological well-being: Meaning, measurement, and implications for psychotherapy research. Psychotherapy and Psychosomatics, 65, 14-23. https://doi.org/10.1159/000289026

Sabuncuoğlu, O., Çevikaslan, A., \& Berkem, M. (2003). Depression, anxiety and behavior in adolescents in two different regions affected by Marmara earthquake. Clinical Psychiatry, 6, 189-197.

Stroebe, M. S., \& Schut, H. (2001). Models of coping with bereavement: A review. In M. S. Stroebe, R. O. Hansson, W. Stroebe, \& H. Schut (Eds.), Handbook of bereavement research: Consequences, coping, and care (pp. 375-403). American Psychological Association. https://doi.org/10.1037/10436-016

Suldo, S. M., \& Huebner, E. S. (2004). Does life satisfaction moderate the effects of stressful life events on psychopathological behavior during adolescence? School Psychology Quarterly, 19(2), 93-105. https://doi.org/10.1521/scpq.19.2.93.33313

Thompson, S. (2002). Older people. In N. Thompson (Ed.), Loss and Grief. A Guide for Human Services Practitioners. Palgrave, London. https://doi.org/10.1007/978-1-4039-1404-0_12

Walker, P., \& Shaffer, M. (2007). Reducing depression among adolescents dealing with grief and loss: a program evaluation report. Health \& Social Work, 32(1), 67-68. https://doi.org/10.1093/hsw/32.1.67

Weiss, R. S. (2001). Grief, bonds, and relationships. In M. S. Stroebe, R. O. Hansson, W. Stroebe, \& H. Schut (Eds.), Handbook of bereavement research: Consequences, coping, and care (pp. 47-62). Washington, DC: APA. https://doi.org/10.1037/10436-002

Weisz, J. R., \& Hawley, K. R. (2002). Developmental factors in the treatment of adolescents. Journal of Consulting and Clinical Psychology, 70, 21-43. https://doi.org/10.1037//0022-006X.70.1.21

Wentworth, R., \& Parks, C. (2006). Social support and self-esteem: Contributing factors in community involvement. Mid-western Psychological Association, Convention Presentation. https://doi.org/10.1037/e564802007-001

Wentzel, K. (1998). Social relationship and motivation in middle school: The role of parents, teacher, and peers. Journal of Educational Psychology, 90(2), 202-207. https://doi.org/10.1037/0022-0663.90.2.202

Weymont, D., \& Rae, T. (2006). Supporting young people coping with grief, loss and death. London: Paul Chapman. https://doi.org/10.4135/9781446279625

Wight, R. G., Botticello, A. L., \& Aneshensel, C. S. (2006). Socioeconomic context, social support, and adolescent mental health: A multilevel investigation. Journal of Youth and Adolescence, 35(1), 109-120. https://doi.org/10.1007/s10964-005-9009-2

Worden, W. (2001). Grief counselling and grief therapy: A handbook for the mental health practitioner. New York: Brunner-Routlege.

\section{Copyrights}

Copyright for this article is retained by the author(s), with first publication rights granted to the journal.

This is an open-access article distributed under the terms and conditions of the Creative Commons Attribution license (http://creativecommons.org/licenses/by/4.0/). 